\title{
Effect of Quenching and Tempering Treatment on the Microstructure and Properties of Q345B Casting*
}

\author{
Biao Wang ${ }^{\mathrm{a}}$, Shifu Chen ${ }^{\mathrm{b}^{* *}}$ and Wenkai Chen ${ }^{\mathrm{c}}$ \\ School of Resources and Materials, Northeastern University, Qinhuangdao Branch, \\ Qinhuangdao, 066004, China; \\ awangbiao320@163.com, bchensf93@163.com, chenwenkai3006@126.com
}

\begin{abstract}
Keywords: metal material, Q345B steel, quenching and tempering treatment, microstructure and properties, the optimum treatment.
\end{abstract}

\begin{abstract}
This paper mainly discusses the effects of heat treatment of Q345B steel at $900 \sim 1060^{\circ} \mathrm{C}$ quenching $+450^{\circ} \mathrm{C}$ tempering treatment on the performance of steel. After heat treatment, the steel samples of different treatments were taken to observation and test to get the statistical analysis of test results by changing heat treatment on the properties of the steel. Results show that the quenching treatment enhances the strength and hardness of the steel significantly. After tempering at $450^{\circ} \mathrm{C}$, the plasticity and toughness of steel has also been picked up. The steel has good corrosion resistance when the quenching at $980 \sim 1020^{\circ} \mathrm{C}$. Considering the strength, hardness, plasticity and toughness, and the heating temperature, production practice, the heat treatment treatment of quenching at $940^{\circ} \mathrm{C}+450^{\circ} \mathrm{C}$ tempering of steel samples, can make the steel obtain excellent comprehensive properties, which is of great economic significance and practical significance.
\end{abstract}

In recent years, high strength low alloy steel production in our country increases year by year [1], but in the strength, quality, variety series and other aspects there is a gap with foreign advanced level, so it is still a considerable number to import high strength and toughness steel[2-6]. Many foreign researchers already can more accurately predicate and calculate HSLA(high strength low alloy) steel high temperature deformation with microstructure-property prediction method [7-8], and get steel hardened by controlling the morphology of ferrite, even having a better effect than the Peierls-Na-barro strength and solid-solution strengthening[9-10], Japan in terms of earthquake-resistant building steel represents the world advanced level, has developed a series of high-intensity strength 590-1275MPa seismic reinforcement[11].Q345B steel is the largest output and the most widely used high-strength low-alloy steel in our country, Q345B steel-solidified shell plasticity will be low at high temperature, and is prone to produce intergranular cracks under strong cooling intensity and uneven cooling condition[12]. Both domestic and foreign metallurgical workers are unclear to the performance and microstructure changes of continuous casting slab in high temperature treatment [13]. However quenching and tempering can eliminate residual stress inside, steady microstructure, adjust the hardness, strength, plasticity and toughness [14]. According to the performance requirements in different environments, exploring quenching and tempering treatment, fully tapping potential performance of Q345B steel, and obtaining high level-mechanical properties and excellent performance of various materials, is the development trend of new generation of steel materials[15], can greatly enhance the value of materials.

\section{Experimental Materials and Method}

Components of Q345B steel samples tested are: C 0.16, Si 0.36, Mn 1.37, P 0.016, S 0.007, Nb 0.026 , the rest is $\mathrm{Fe}[16]$, measurement results of the critical point are: $\mathrm{Ac} 1=770^{\circ} \mathrm{C}, \mathrm{Ac} 3=917^{\circ} \mathrm{C}, \mathrm{Ms}=$ $400^{\circ} \mathrm{C}$ [17]. So take 5 samples of $150 \mathrm{~mm} \times 8 \mathrm{~mm} \times 7 \mathrm{~mm}$ and another 5 of $25 \mathrm{~mm} \times 8 \mathrm{~mm} \times 7 \mathrm{~mm}$ at 900 , $940,980,1020$ and $1060^{\circ} \mathrm{C}$ for insulation, with water as the quenching medium. Set the tempering temperature at $450^{\circ} \mathrm{C}$, after tempering take 6 samples of $25 \mathrm{~mm} \times 8 \mathrm{~mm} \times 7 \mathrm{~mm}$ for grinding, polishing and corroded by $4 \%$ nitric acid alcohol solution, then observing their microstructure by DMI5000M-metallographic microscope. 
Take 6 steel samples of $150 \mathrm{~mm} \times 8 \mathrm{~mm} \times 7 \mathrm{~mm}$ for tensile experiment by WDW3100 micro-control electronic universal testing machine; and take other 6 steel samples of $25 \mathrm{~mm} \times 8 \mathrm{~mm} \times 7 \mathrm{~mm}$ for hardness test by Rockwell Hardness Tester, to acquire change information of Q345B steel in mechanical properties; Cut to get 6 samples of $150 \mathrm{~mm} \times 8 \mathrm{~mm} \times 7 \mathrm{~mm}$ by Metallographical Cutter, take 6 steel samples of $5 \mathrm{~mm} \times 8 \mathrm{~mm} \times 7 \mathrm{~mm}$ to make working electrode, and prepare $\mathrm{w}=3.5 \%$ of $\mathrm{NaCl}$ solution(as corrosion solution), then make electrochemical corrosion experiment by CS150-LK2005A type electrochemical test system, to get change information of Q345B steel in corrosion resistance; Grind fractures of the 6 tensile samples and bottom surfaces of the 6 corrosion samples whose corrosion surface are preserved well, and make electric mirror scan with SPURA 55 type electric mirror, observe the morphology of tensile fractures and judge the plasticity and toughness of treated steel.

\section{Results and Analysis}

\subsection{Tensile test analysis of Q345B steel after heat treatment}

Get test force-displacement data through simulation tensile experiment, and respectively divide them by the cross-sectional area and the standard distance $(50 \mathrm{~mm})$, map and get the stress-strain curve. Performance changes of treated steel samples, as shown in Figure 1-4.
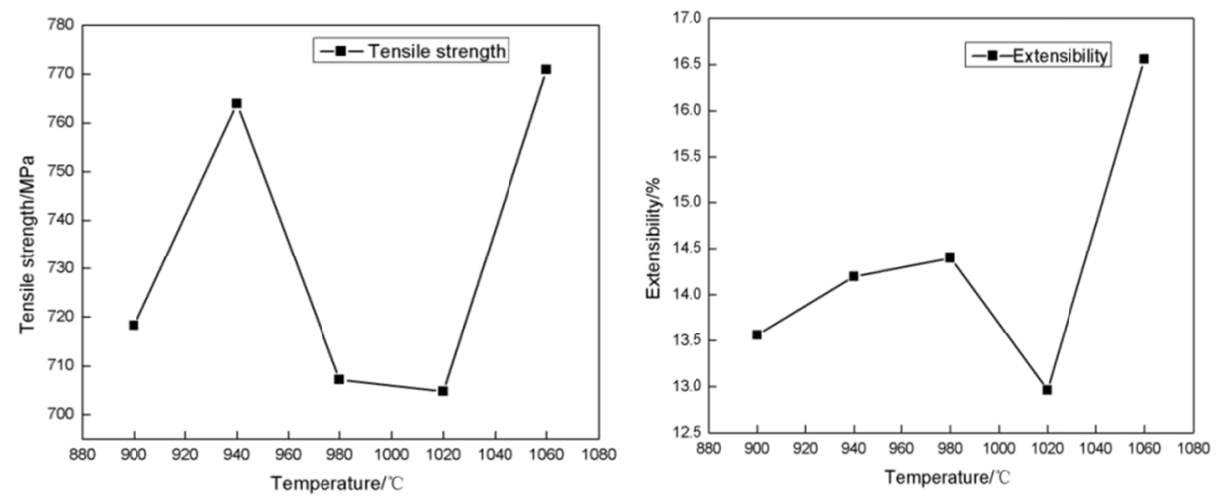

Fig.1 The tensile strength change

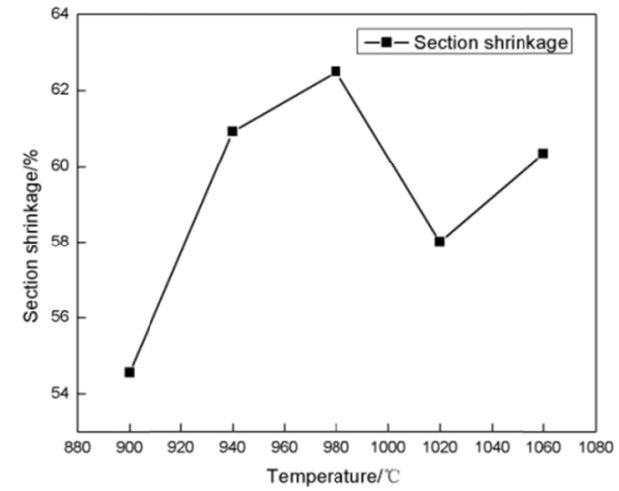

Fig.2 The extensibility change

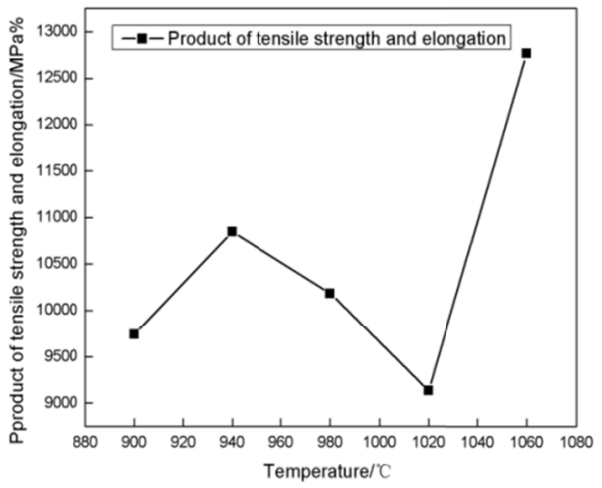

Fig.3 The section shrinkage change Fig.4 The product of tensile strength and elongation change

Properties of untreated steel: the tensile strength is $516.54 \mathrm{MPa}$, the extensibility is $25.2 \%$, the the section shrinkage is $62.58 \%$, the product of tensile strength and elongation is $13016.81 \mathrm{Mpa} \%$. Observation of treated steel: (1)Strength: Quenching treatment can significantly increase the value of ob by $40 \% \sim 50 \%$, $\sigma \mathrm{b}$ has a peak when quenching at about $940^{\circ} \mathrm{C}$, and above $1050^{\circ} \mathrm{C}$ ob will rise with temperature increasing. (2)Plasticity: Quenching treatment can reduce the plasticity, the extensibility and the section shrinkage, the extensibility decrease by $35 \% \sim 50 \%$, elongation after fracture and reduction of area are higher when quenching temperature at $980^{\circ} \mathrm{C}$, and rise when temperature exceeds $1050^{\circ} \mathrm{C}$. (3) Static toughness: quenching treatment can reduce streng,th and ductility, when temperature exceed $1050^{\circ} \mathrm{C}$ strength and ductility has an upward trend. 
Consider impacts of microstructure changes of steel on mechanical properties, it can be analyzed: quenching treatment increased the strength of steel and reduced its plasticity and static toughness, mainly due to the emergence of high strength martensite and the decrease of soft ductile phase ferrite inside the quenching microstructure. There are many reasons for martensite to have high strength, mainly including the solid solution precipitation of carbon atom, phase transition strengthening and aging strengthening. Meanwhile, during tempering treatment after quenching, the desolventizing precipitation of carbon atoms in martensite, decomposition of quenching martensite, formation of quenched martensite, cementite growing up together and other treatmentes, to some extent, reduce tensile strength of quenching steel, but bring it a better improvement on plasticity and toughness, making the steel be both good in strength and plasticity and toughness and obtain high comprehensive properties and use value.

\subsection{Rockwell hardness test analysis of Q345B steel after heat treatment}

The hardness changes of treated steel samples, as shown in Figure 5. Average hardness of untreated steel is 51.3HRA, observe quenched steel sample, we can see quenching treatment increased the steel hardness, by around $10 \%$, and hardness value will reduce with increasing quenching temperature.

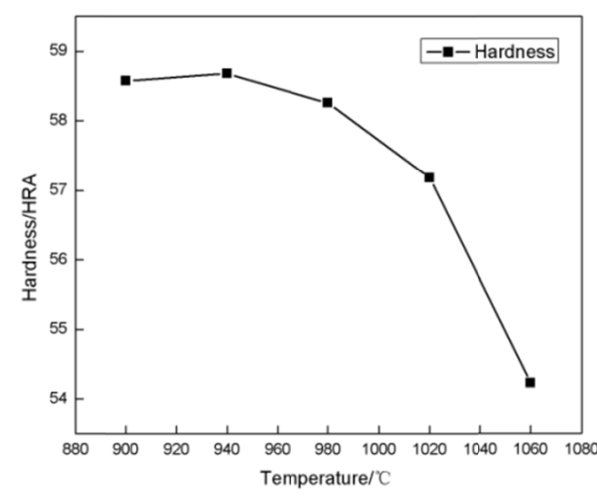

Fig.5 The hardness

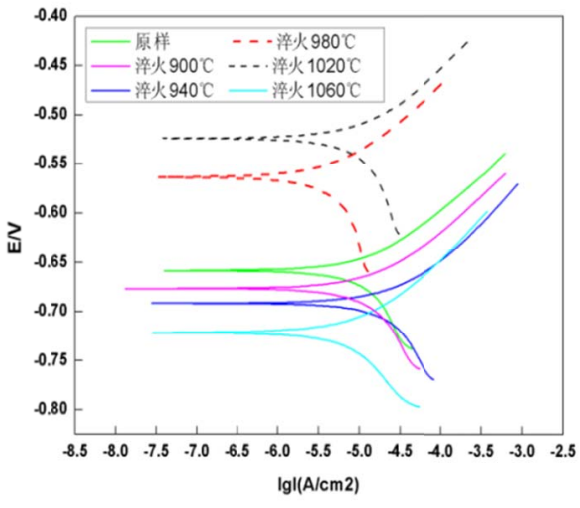

Fig.6 Tafel curve

Consider the impacts of steel microstructure-changes on hardness, it can be analyzed: quenching treatment can increase steel hardness, which mainly due to the appearance of high strength martensite and the reduction of soft ductile phase ferrite in the quenching structure, and with quenching temperature increasing, original austenite grain become larger, the size of martensite laths formed in quenching also increases, causing the hardness decreases slightly. Meanwhile, during tempering treatment after quenching, the desolventizing precipitation of carbon atoms in martensite, decomposition of quenching martensite, formation of quenched martensite, cementite growing up together and other treatment reduce the hardness of quenching steel and make the steel good in strength and plasticity and toughness.

\subsection{Q345B steel after heat treatment analysis of the kinetics of electrochemical corrosion experiment}

According to the first experiment data of working electrode in each group, obtaining Tafel curves shown in Figure 6. Corrosion resistance are in the order: quenching $1020^{\circ} \mathrm{C}>$ quenching $980^{\circ} \mathrm{C}>$ original sample, quenching 900,940 and $1060^{\circ} \mathrm{C}$. Actual situation: when steel surface soaked in $\mathrm{w}=3.5 \% \mathrm{NaCl}$ solution, it occurs almost general corrosion (only a few pitting). Comprehensively consider the relative position between the Tafel curves, we can know steel has good corrosion resistance when quenching temperature is at $980 \sim 1020^{\circ} \mathrm{C}$.

\subsection{Analysis of the tensile sample fractures}

After treatment the fracture of steel sample was ductile fracture, along with the necking. By observing its macroscopic fracture with stereo-microscope, finding it fibrous fracture, or in other words, plastic toughness fracture. 


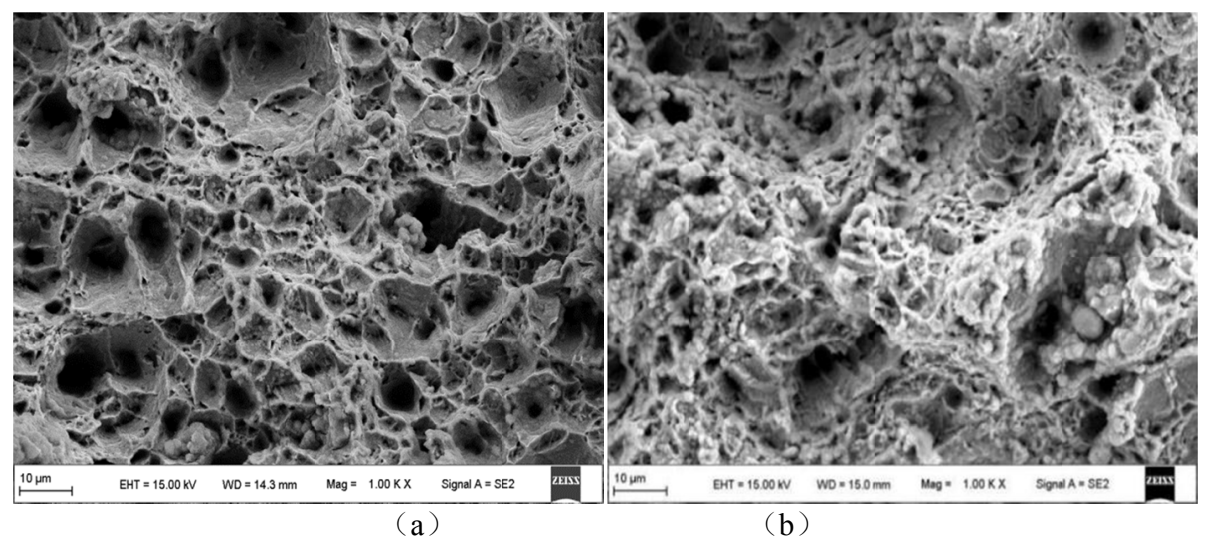

Fig.7 Fracture morphology of magnified 1000 times: $a$ is original steel samples and $b$ is $900^{\circ} \mathrm{C}$ quenching $+450^{\circ} \mathrm{C}$ tempering steel samples

Observing by scanning electron microscope, it shows that original sample and treated sample both have a certain amount of equiaxed dimples, fracture are transgranular fracture, which belongs to the ductile fracture. There are many big cavity dimples in original sample fractures, large particle inclusions formed by $\mathrm{MnS}$ are in the center [18], or big dimples formed by particle inclusions $\mathrm{MnS}$ clip debris peeling formed, also has small of MnS clip debris formed of many small dimples, become the bridge of connecting empty big dimples. By dimples of $\mathrm{MnS}$ inclusions formed in series with each other, cause the sample fracture.

Search information and obtain the following table[19]:

Table 1 Inclusion cracking way of critical crack size and strain

\begin{tabular}{cccc}
\hline \multirow{2}{*}{ Inclusion } & The critical $\varepsilon / \%$ & $\begin{array}{c}\text { Inclusion crack of critical } \\
\text { size L/um }\end{array}$ & Inclusion cracking \\
\hline \multirow{3}{*}{$\mathrm{MnS}$} & 0.1 & 57.8 & itself \\
& 3.0 & 20.4 & itself \\
& 5.0 & 13.6 & itself \\
& 18.0 & 3.4 & itself \\
\hline
\end{tabular}

The presence of inclusions destroy the continuity of the matrix, which makes the stress transmission mode between inclusions and matrix become different, under the external force, around inclusions first appear stress concentration, causing plastic deformation, therefore produce a large amount of dislocation pile-up around inclusions[20]. When the stress of dislocation pile-up reaches a fracture strength of inclusions or interfacial strength of inclusions and matrix, inclusions will crack or separate from matrix interface and form microcracks. Microcracks constantly expand and interconnect with each other, finally cause the fracture. According to the table above: When the strain is very small, only the large inclusions begin to crack, however as the strain increases constantly, the smaller $\mathrm{MnS}$ inclusions begin to crack too, meanwhile the crack number inside large inclusions will gradually increases and separate from the interface and finally form cavity.

In the treated steel sample fractures, with the number of dimples which sitand for plasticity and toughness relatively decreases, density of dimples become smaller than original sample fractures, causing the plasticity and toughness of quenched steel become lower. Meanwhile there are some micro twin martensite in martensite lath formed in the quenching, Hu Gengxiang et al. point out that, the existence of micro twin martensite is the root cause of micro-cracks to produce and propagate, it makes the number of effective slip systems in deformation become smaller significantly and increase the deformation resistance, thus cause stress concentration and make steel toughness decrease and steel brittleness increase[21]. 


\section{Summary}

1. Quenching and tempering treatment significantly improve the tensile strength and hardness of steel, strength increases by about $40 \%$ to $50 \%$. When the quenching temperature at about $940^{\circ} \mathrm{C}, \sigma \mathrm{b}$ have a peak, and $\sigma \mathrm{b}$ will have a upward trend with temperature rising above $1050^{\circ} \mathrm{C}$.As the quenching temperature increases, the steel hardness decreases conversely.

2. Quenching and tempering treatment reduce the plasticity, elongation after fracture and reduction of area of steel. However, due to the appropriate tempering temperature of $450^{\circ} \mathrm{C}$, fracture of quenched steel samples are still ductile fracture, by scanning the fracture there is a certain amount of dimples in fracture which stand for plasticity and toughness, so sample can maintain high plasticity and toughness after tempering.

3. The corrosion resistance of the steel: the steel has good corrosion resistance when quenching temperature at $980 \sim 1020^{\circ} \mathrm{C}$.

4. Comprehensively consider the strength, hardness, plasticity and toughness and heating temperature, when quenching temperature at $940^{\circ} \mathrm{C}$, the steel microstructure has the right size of martensite, and steel samples are maintained at higher levels in strength, hardness, plastic and toughness etc. And the heating temperature not very high also meets requirements of environment and resources. Considering actual production, quenching $940^{\circ} \mathrm{C}$ and tempering $450{ }^{\circ} \mathrm{C}$ heat treatment can get excellent performance of steel, has great economic significance and practical significance.

\section{Acknowledgements}

I would like to express my gratitude to all those who helped me during the writing of this thesis. My deepest gratitude goes first and foremost to my supervisor----Wang Biao, for his constant encouragement and guidance. He has walked me through all the stages of the writing of this thesis. Without his consistent and illuminating instruction, this thesis could not have reached its present form. I also owe my sincere gratitude to my teammates who gave me their help and time in listening to me and helping me work out my problems during the difficult course of the thesis.

*Surported by National Science Guidance of Hebei Education Department Program No.Z2010217.

\section{References}

[1] Yuqing Weng, Caifu Yang, Chengji Shang. The State of Art and Development Trends of HSLA Steels in China [J]. Journal of Iron and Steel Research (International), 2011, S1:1-13.

[2] Pingguang Xu, Bingzhe Bai, Hongsheng Fang. Current Status and Development of High Strength Low Alloy Steel Plate [J]. Materials for Mechanical Engineering, 2001, 25(2):1-1.

[3] Zeping Gao.Approach to Strengthening Mechanism and Production treatment of Low-Alloy-High Strength steel [J]. Hunan Metallurgy, 2001, 01:17-20.

[4] Tao Dong, Junyan FU. Prospect of Chinese Steel Industry and Nb-microalloyed Steel in the 21th Century[R].Beijing: The Round Table Discussion of "Prospect for New Century Development of Nb-microalloyed Steel Science-technology", 1999.

[5] TableShikanai Nehuo, Mitao Shinji, Endo Shigero. Recent Development in Microscructural Control Technologies Through the Thermo-Mechanical Control treatment (TMCP) withJFE Steel's High-Performance Plates[J]. JFE Technical Report, 2008(11), 1.

[6] Mabuch H.Metallurgical Features of Steel Plats With Ultra Fina Grains in Surface Layers and Their Formation Mechanism [J]. ISIJ International, 1999, (5):479-483

[7] Hodgson P D, Gibbs R K. A mathematical model to predict the mechanical properties of hot rolled C-Mn and microalloyed steels [J]. ISIJ International, 1992, 32(12):1329-1334. 
[8] Porier J P. Crystals of high temperature plastic deformation [M]. Dalian: Dalian University of Technology Press, 1989, 25.

[9] Garcia CIssac, Suikkanen Pasi P, Deardo Anthony J.Modern Microalloyed Steels [J]. Journal of Iron and Steel Research (International), 2011, S1:14-21.

[10] Carlos Garcia-Mateo, Carlos Capdevila, Juan Cornide, etal. Influence of V (C, N) Precipitates on Microstructure and Me-chanical Properties of Continuous Cooled C-Mn-V [J]. Journal of Iron and Steel Research (International), 2011, S1:266-270.

[11] Caifu Yang. Latest technology progress of high strength steel [C]. Beijing:The Chinese Society For Metals, 2009:103.

[12] Tianyi Wang. Technology practice of thin slab continuous casting and rolling [M]. Beijing: Metallurgical Industry Press, 2005.

[13] Dengfu CHEN, Xingjian GAO, et al. High temperature mechanical properties analysis of Q235G steel continuous casting billet [J] .The Chinese Journal of treatment Engineering, 2009, 9(1):10-13.

[14] Xi De. Study on Technology and Property of Q390 and Q345B Steels by Induction Tempering [D].Baotou: Lnner Mongolia University of Science \& Technology, 2012:3.

[15] WANG Guo-dong, LIU Xiang-hua, ZHU Fu-xian, etal. Present Situation of Studying a New Generation Iron and Steel material and Its Development Tendency [J]. Angang Technology, 2005, 04:1.

[16] Cheng Su. The research on high temperature mechanical properties of micro-alloyed Q345B structural steel [D]. Baotou: Lnner Mongolia University Of Science \& Technology, 2011

[17] Wu Lin, Xiwang Zhang, Yankuo ZHAO, et al. Continuous cooling transformation cyrve of undercooling austen ite about Q345 steel [J]. Materials Science and Technology, 2009(2):247-250.

[18] Jianping Zheng, Zhenyi Huang, Hui Jiang, et al. Microstructure in Lam inated Tensile Specimens of Q345B Steel after Rolling [J]. Heat Treatment, 2009, 24(1):42-46.

[19] Jingyuan Li, Weiyi Zhang, Chengfu Wei, et al. The inclusions in steel and steel properties and the fracture [M]. Beijing: Metallurgical Industry Press, 2012:516.

[20] Zhiyi Wang, Kexiang Le. Analysis on the Cause of Fracture Lamination during Tensile Test of Q345B Medium Plate [J].Wide and Heavy Plate, 2009, 15(3):11-14.

[21] Zhilan Ren, Minghua Tang, Shuangkai $\mathrm{Hu}$, et al. Influence of quenching treatment on microstructure and properties of large diameter oil casing [J]. Transactions of Materials and Heat Treatment, 2012, 33(12):116-120. 